$1-2015$

\title{
The Next Generation of Computational Science and Engineering
}

George K. Thiruvathukal

Loyola University Chicago, gkt@cs.luc.edu

Follow this and additional works at: https://ecommons.luc.edu/cs_facpubs

Part of the Computer Sciences Commons

\section{Recommended Citation}

George K. Thiruvathukal, "The next Generation of Computational Science and Engineering", Computing in Science and Engineering, January-February 2015, 10.1109/MCSE.2015.26.

This Article is brought to you for free and open access by the Faculty Publications and Other Works by Department at Loyola eCommons. It has been accepted for inclusion in Computer Science: Faculty Publications and Other Works by an authorized administrator of Loyola eCommons. For more information, please contact ecommons@luc.edu. c) (†) $\ominus$

This work is licensed under a Creative Commons Attribution-Noncommercial-No Derivative Works 3.0 License. Monthly EIC messages are open access. 


\section{FROM THE EDITORS}

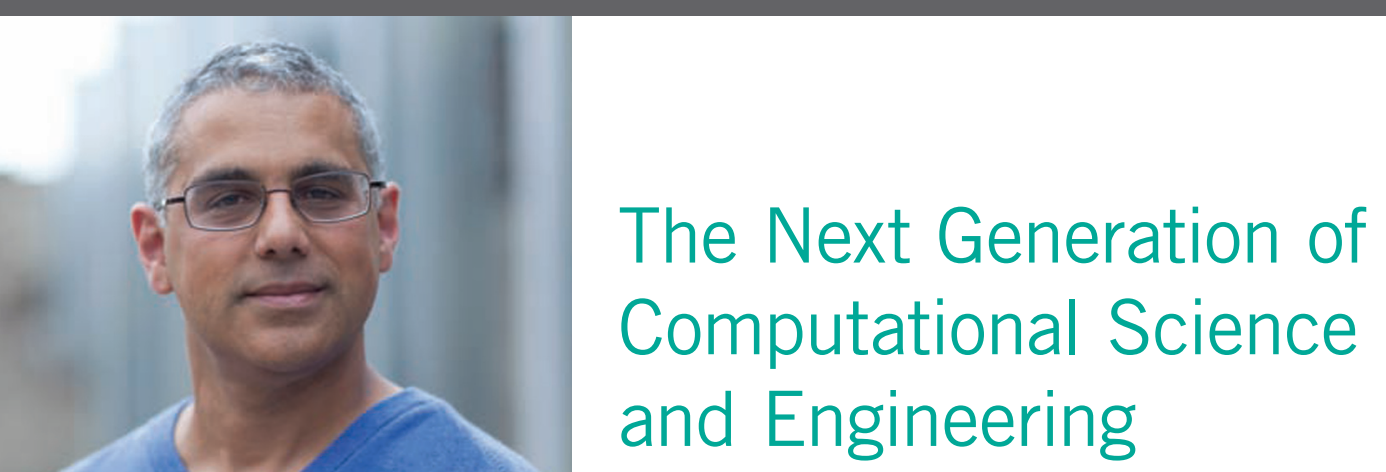

by George K. Thiruvathukal Loyola University Chicago

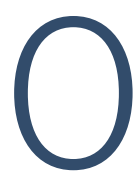

ver the past few months, I've been thinking a lot about my career and how to maximize impact, by which I don't necessarily mean scholarly impact. For me, it all started as a software developer with many interdisciplinary interests outside the purview of what might be termed my day job (a euphemism for what I get paid to do at any given time). Like many and not so many in the field, I've been pondering how richly blessed I am to be employed in a profession that also doubles as one of my hobbies. I'm even more blessed to be an editor of an excellent publication that values the intersection of computer science with other disciplines.

When I became EIC of CiSE, I was particularly delighted at all of the interdisciplinary content that makes CiSE what it is. This is in no small part to the excellent work of many of my predecessors who served as EIC, from Francis Sullivan (who was the EIC when I wrote my first CiSE article), to Norman Chonacky, to Isabel Beichl. These interdisciplinary editors were each able to see beyond their disciplinary training and think about how to leave their mark —or better put, imprimatur—on CiSE, so to speak. As I enter the second half of my time as EIC, I'm already coming to terms with the fact that this important and defining work of my career may well be drawing to a close. Crazy though it may sound, I'm not the least burned out as EIC and still feel like I have a lot of work to do.

\section{And Now for Something Completely Different (or the Same)}

As you all know by now, you're either reading this editorial or not. You're in a state similar to Schrödinger's Cat, a paradox learned by most of us in the wonderful course known as Quantum Mechanics (which either leaves you loving physics or lost beyond hope). As well, you know that you're now reading (or not reading) the digital version of CiSE, because unless you opted for a deal that you couldn't refuse (or chose to refuse) you're probably not getting the print version of CiSE. No matter what, you can't actually be in both states (reading and not reading), for doing so would defy the basics of Boolean logic (True and not True $=$ True, which is False). Anyway, I sure hope you're reading, but I think reading is going to take on a different character in the future. In one scenario, folks will continue to read my editorial. In another scenario, folks will read whatever they want (or are directed) to read—say, through carefully placed keywords. But will they read my editorial? Time will tell.

\section{So What Comes Next}

It's natural to wonder, what comes next? Will a space probe land on a comet, or will the EIC get back to the topic of his article?

Each EIC brings a different set of experiences and institutional strengths with him (or her). In my case, I'm a professor at a Jesuit Catholic university. No, you're not about to get any sort of lecture on the Jesuits or Catholicism (and I'm not either, so I wouldn't exactly be qualified to write about it). But I think in the nearly 15 years that I've been at Loyola University Chicago, I've become convinced of the great value of looking beyond your own discipline to understand other pressing issues in the world. I truly think CiSE needs to expand its focus twofold: by doing a complete review of what we do and how it can be more relevant. You're going to see some of these changes coming down the pike.

With this issue, I'm planning to expand our focus on community. If there's anything that makes CiSE great, it's our community. More importantly, it's an example of 
communities of practice (see http://en.wikipedia.org/wiki/Community_of_practice). This is in keeping with Jean Lave and Etienne Wenger's idea that a community of practice involves "a group of people who share a craft and/or a profession." I won't spoil the guest editors' introduction (even though I co-authored it), but the development of scientific and engineering software is something that deserves special, regular attention of our publication. It's not always the sort of thing that journals and conferences want to focus on, but without real, working software, it's hard to imagine our own existence. Toward this end, I'll be working with my editorial board to expand this notion of communities of practice. We have many such examples. Our recent issues on leadership computing are an example of communities of practice focusing on the high end of scientific/technical computing, mostly at national and international laboratories - and often using supercomputers. For a long time, I've felt that this community wasn't much of a focus of CiSE, yet they were highly interested in what we do. After a few meetings with folks from Argonne National Laboratory, we decided to include this community of practice in our focus.

This takes me to another community of practice, which is well-represented in the current issue. There are many communities working on the development of scientific software. Not all of these folks work on supercomputing. In fact, many of the projects are used in the mainstream for non-scientific projects. For example, there are very well-known Python-based library projects, such as NumPy, SciPy, and so on. I've seen these projects used in a number of scientific and non-scientific projects alike, including projects for natural language processing, electronic music, and many others. Many of the folks doing these projects are outside of the academy and often work on them as a hobby, yet they've risen to real prominence. CiSE has an important place in these communities, and it may well be one of the only ways that their work can be recognized (beyond GitHub and Bitbucket, where they're often hosted).

W hat other, more important things can we be doing? In my work to chair the IEEE Computer Society's Special Technical Community on Broadening Participation, we're working to expand our discussion of matters of representation (race, ethnicity, and gender, among criteria) in computing (and STEM in general). I'm working to ensure that these issues are covered in CISE. It goes almost without saying that our field does suffer because of diversity issues, and we should be concerned with the lack of gender, racial, and ethnic diversity in many of the countries where our publication is received. As one of the cornerstones of my own university's mission is to work for social justice and expand opportunity to everyone, I cannot think of any good reason not to address this issue in CiSE. If it's good for our co-sponsoring organization, it's also good for us. But more importantly, it will lead to a focus beyond the traditional disciplines we cover and, I hope, a corresponding increase in the board's diversity and our overall way of thinking. Anyway, you'll likely see a special issue and possible department forming around this and the aforementioned communities of practice.

Now, with that said, whether you're still reading this (or not), please like and follow us on Facebook (https://www.facebook.com/CiSEmagazine) and Twitter (https://twitter. com/cisemag)!

George K. Thiruvathukal is a full professor in the Computer Science Department at Loyola University Chicago, where he also directs the Center for Textual Studies and Digital Humanities. $\mathrm{He}$ is also a guest faculty member at Argonne National Laboratory in the Mathematics and Computer Science Division, working on runtime environments and software to support computational biology applications. His research interests span multiple areas of computer science and interactions with science and the humanities. Thiruvathukal has a $\mathrm{PhD}$ in computer science from the Illinois Institute of Technology. He is the editor in chief of CiSE and an associate editor for Computing Now. Contact him at gkt@cisemagazine.org. 